\title{
Frequency of symptoms of attention deficit and hyperactivity disorder in autistic children
}

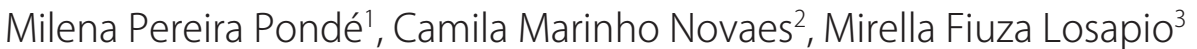

\begin{abstract}
Background: Both DSM-IV and the ICD-10 exclude diagnosis of attention deficit/hyperactivity disorder (ADHD) when autism diagnostic is present. Some authors suggest, however, that autism can be associated to other comorbidity amongst which the ADHD. Objective: To estimate prevalence of ADHD in children with autism. Method: Children were selected from a specialized school, all of then had previous diagnosis or diagnostic suspicion of autism. The Brazilian version of the KIDDIE-SADS PL was applied to parents for diagnostic of ADHD. DSM-IV diagnostic of autism was based on parents' interview and child observation. Results: 32 children were included in the study. Results show that $53.1 \%$ of the ASD child had ADHD symptoms enough to fulfill DSM-IV diagnostic criteria, whereas $56.9 \%$ did not fulfill DSMIV criteria for ADHD. Conclusion: Results suggest a high frequency of ADHD symptoms in ASD patients. Elucidating if we are facing a comorbity or an autism distinct phenotype can contribute for a more adjusted pharmacotherapy approach for these children. Key words: autistic disorder, attention deficit disorder with hyperactivity; prevalence, comorbidity.
\end{abstract}

Freqüência de sintomas de transtorno de déficit de atenção e hiperatividade em crianças autistas

\section{RESUMO}

Tanto o DSM-IV quanto a CID-10 excluem o diagnóstico de transtorno de déficit de atenção e hiperatividade (TDAH) em pacientes autistas. A literatura, no entanto, sugere que o autismo pode estar associado a outras doenças, dentre elas o TDAH. Objetivo: Estimar a freqüência de sintomas de TDAH em autistas. Método: As crianças foram selecionadas de uma escola especializada em crianças com transtorno do espectro autista (TEA); todas tinham um diagnóstico ou suspeita diagnóstica prévia de autismo. O instrumento de avaliação aplicado para o diagnóstico de TDAH foi a versão brasileira do KIDDIE-SADS PL. O diagnóstico de autismo de acordo com os critérios do DSM-IV foi feito através de entrevista com os pais e observação da criança. Resultados: 32 crianças foram incluídas no estudo. Os resultados indicam que 53,1\% dos pacientes apresentaram sintomas compatíveis com o diagnóstico de TDAH e de autismo, enquanto que $56,9 \%$ dos autistas não preenchiam critérios para TDAH. Conclusão: Os achados sugerem uma elevada freqüência de sintomas de TDAH em pacientes com autismo. Elucidar se estamos diante de uma comorbidade ou de um fenótipo diferente de autismo pode contribuir para uma melhor abordagem farmacoterápica dessas crianças.

Palavras-chave: transtorno autístico, transtorno da falta de atenção com hiperatividade, prevalência, comorbidade.

\section{Correspondence}

Milena Pereira Pondé

Av. Centenário 2883 / 410

40155-150 Salvador BA - Brasil

E-mail: milenaponde@bahiana.edu.br

Received 2 July 2009

Received in final form 10 September 2009

Accepted 14 September 2009
Autism is a chronic developmental disorder characterized by significant impairment in reciprocal social interaction and communication, associated with patterns of restricted, repetitive and stereotyped behavior reducing the focus of activ-

\footnotetext{
'Professor of Bahia School of Medicine and Public Health (EBMSP), Salvador BA, Brazil; ${ }^{2}$ Medical Resident at Santo Antônio Hospital. Scholarship from Bahia Foundation of Research Suport (FAPESB BOL 1733/2006), Salvador BA, Brazil; ${ }^{3}$ Medical student of EBMSP. Scholarship from Bahia Foundation of Research Suport (FAPESB BOL 1930/2008), Salvador BA, Brazil.
} 
ities and interests ${ }^{1}$. Symptoms typically appear between birth and the first 18 months ${ }^{2}$. About $5 \%$ to $10 \%$ of patients with autism become independent adults, $25 \%$ have some improvement, but still need supervision, while the rest remains disabled requiring institutionalization, resulting in high costs for family and community ${ }^{3}$. Some authors suggest that autism is often associated with other morbidities ${ }^{4-22}$, as mental retardation ${ }^{5,6}$, epilepsy ${ }^{7}$, fragile X syndrome ${ }^{8}$, Down's syndrome ${ }^{9}$, bipolar mood disorder, schizophrenia and other psychotic disorders ${ }^{10}$, Tourette's disorder ${ }^{11}$, anxiety and depression ${ }^{5,11,12}$, specific phobia and obsessive compulsive disorder ${ }^{13}$. There seems to be a high prevalence of symptoms of attention deficit and hyperactivity disorder (ADHD) among patients with autism ${ }^{4,11,13-22}$. Both, DSM-IV ${ }^{1}$ and ICD-10, exclude the diagnosis of ADHD in children with autism, whereas the hyperactivity as a symptom associated with those characteristic of autism. Contrary to the recommendations of these manual diagnostics, some authors suggest consideration of comorbidity between ADHD and autism ${ }^{4,11,13-22}$.

$\mathrm{ADHD}$ is one of the most common neuropsychiatric disorder in childhood and is also among the most prevalent chronic disease in school-age children ${ }^{23}$. According to DSM-IV-TR it is characterized by three groups of symptoms which will define the predominant subtype of the disease: combined, predominantly inattentive or predominantly hyperactive/impulsive ${ }^{1}$. In the autistic child seems to exist most commonly the predominant subtype hyperactive-impulsive ${ }^{16}$. Many children with autism show significant deficit in visual attention and impulsivity, however the increased motor activity does not appear to be a specific symptom of autistic spectrum disorder. ADHD symptoms amongst autistic children are understood by current classifications (DSM-IV and IDC-10) as associated symptoms. We can also think that the association of autism and ADHD can be comorbidity or still a distinct phenotype of autism. Elucidating this problem can predict the prognosis for these children and can be very important for therapeutic planning for autistic children ${ }^{24}$, especially because those children have been treated with different classes of medications ${ }^{25}$.

This study aims to estimate the frequency of symptoms of ADHD in patients with autistic disorder.

\section{METHOD}

This is a cross-sectional study to assessed the frequency of ADHD symptoms in autistic patients. Data collection was between September and December 2006 in a school specialized for autistic spectrum disorder children in Salvador, Bahia, Brazil. The institution served $38 \mathrm{stu}-$ dents between 6 and 18 years old, of which 32 was included in this study. Four subjects were excluded from the sample because they were not present in the period of data collection and two because they have others diagnoses into autism spectrum disorders. Parents were asked about socio-demographic data and child's background: gender, age, number of parents with whom the child reside, family history of psychiatric problems, complications during pregnancy (infectious diseases and / or prenatal complications), smoking during pregnancy, birth, complete immunizations, neuropsychomotor developmental delay, medical care and use of medication in the last six months. For evaluation of children ADHD the instrument used was the ADHD session of the Brazilian version of the Schedule for Affective Disorders and Schizophrenia for School-Aged Children (K-SDAS PL) ${ }^{26}$. The KSDAS PL ${ }^{26}$ is a semi-structured diagnostic interview designed to assess episodes of psychopathology in children and adolescents from six to eighteen years old, according to DSM-IV. The interview was administered to parents, and the children were also observed by researcher. The diagnosis of autism was confirmed according to DSM-IV thought interviews with parents and observation of the children. Informations were stored in a database using the statistical program Epi Info 2002, and statistical tests were performed using the statistical program SPSS version 15.0. The study was approved by Ethic Committee from Bahia Foundation for Science Development (FBDC) under Protocol N. 62/2006, and all parents signed the consent form.

\section{RESULTS}

Table 1 summarizes data of the patients in the sample. The average age was 10.5 years, ranging between six and 18 years. The majority was male (90\%), 65.6\% lived with both parents, $37.5 \%$ had family history of psychiatric problems (HFPP), 43.7\% had complications in preg-

Table 1. Characteristics of population.

\begin{tabular}{lcc}
\hline Characteristics & N & $\%$ \\
\hline Male & 29 & 90 \\
More than 10 years old & 14 & 43.7 \\
Living with parents & 21 & 65.6 \\
FHPD & 12 & 37.5 \\
Complications during pregnancy & 14 & 43.7 \\
Smoke during pregnancy & 1 & 3.1 \\
Birth at term & 30 & 93.7 \\
Full immunization & 30 & 93.7 \\
Psychomotor development delay & 32 & 100 \\
Medical assistance (less than 1 year) & 27 & 84.3 \\
Medication use (last 6 months) & 22 & 68.7 \\
ADHD & 17 & 53.1 \\
\hline
\end{tabular}

FHPD: family history of psychiatric disorder; ADHD: attention-deficit/ hyperactivity disorder. 


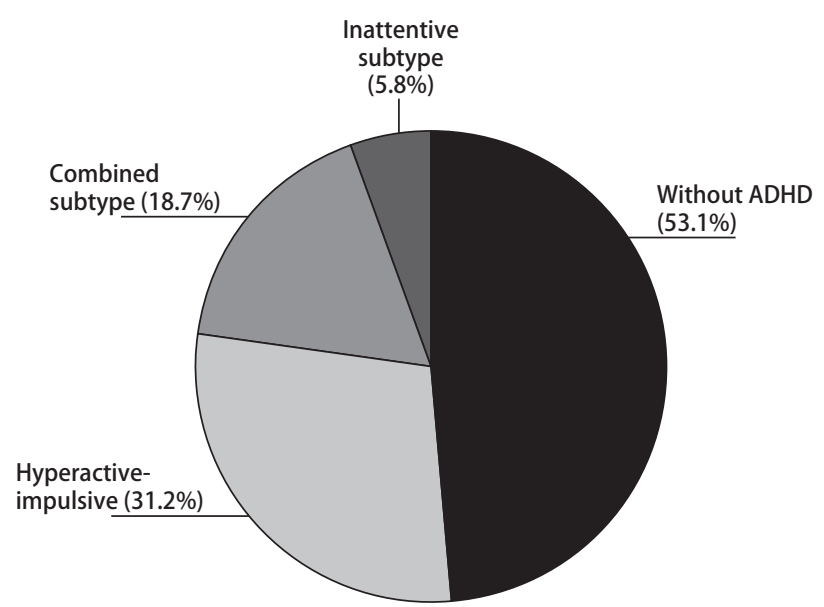

Figure. Subtypes of ADHD.

nancy. Only one mother (3.1\%) smoked during pregnancy, $93.7 \%$ of patients were born at term and had complete immunizations for their age, $84.3 \%$ received medical attention in the last year and $68.7 \%$ made use of any medication in the last six months.

With regard to ADHD symptoms, 17 patients (53.1\%) had enough symptoms to fulfill DSM-IV diagnosis of ADHD and 15 don't have symptoms. Of these 15, 5.8\% met criteria for the inattentive subtype, $31.2 \%$ for hyperactive-impulsive and $18.7 \%$ for combined subtype (Figure).

Table 2 shows the comparison of patients with and without ADHD symptoms. The two groups did not differ with respect to gender, age, living environment, family history of psychiatric illness, smoking during pregnancy, pregnancy to term, complete immunization, psychomotor delay, difficulty in adjustment and medical monitoring in the last year. The only variable that distinguished the two groups was current use of psychiatric medication $(p<0.0032)$, which was more frequent in the ADHD group.

In the group of children with ADHD symptoms of 94.1\% were using one or more of the following medications: periciazine, thioridazine, levomepromazine (in Germany and methotrimeprazine in America), trifluoperazine, risperidone, carbamazepine, valproate sodium, oxcarbazepine, fluoxetine and clonazepam. Only six patients $(40.0 \%)$ were using medication in the group that did not have ADHD symptoms.

\section{DISCUSSION}

Autism is a complex developmental disorder with multiple etiologies and different severity degrees ${ }^{25}$. These disorder is commonly associated with other morbidities ${ }^{4-22}$. Recent studies indicate that the co-occurrence of clinical symptoms of ADHD and autism are common ${ }^{4,11,13-22}$.

The results of this study corroborate the data in the literature to indicate a high frequency of ADHD symptoms
Table 2. Social demographic data of patients evaluated.

\begin{tabular}{lcc}
\hline \multicolumn{1}{l}{$\begin{array}{c}\text { with } \\
\text { ADHD }\end{array}$} & $\begin{array}{c}\text { without } \\
\text { ADHD }\end{array}$ \\
\hline $\begin{array}{lcc}\text { Gender } \\
\text { Male }\end{array}$ & $15(88.2 \%)$ & $13(86.6 \%)$ \\
Female & $2(11.8 \%)$ & $2(13.4 \%)$ \\
Age & & \\
$\leq 10$ years & $8(47.1 \%)$ & $(53.4 \%)$ \\
$>10$ years & $9(52.9 \%)$ & $7(46.6 \%)$ \\
Living environment & & \\
1 genitor & $6(35.3 \%)$ & $4(26.6 \%)$ \\
2 genitors & $11(64.7 \%)$ & $(73.4 \%)$ \\
FHPD & $8(47.1 \%)$ & $(26.6 \%)$ \\
Smoke during pregnancy & $1(5.9 \%)$ & $0(0 \%)$ \\
Birth at term & $15(88.2 \%)$ & $15(100.0 \%)$ \\
Full immunization & $17(100.0 \%)$ & $13(86.6 \%)$ \\
Psychomotor delay & $17(100 \%)$ & $15(100 \%)$ \\
Adaptive difficulties & $17(100 \%)$ & $15(100 \%)$ \\
Monitoring in the last year & $16(94.1 \%)$ & $11(73.3 \%)$ \\
Medication use* & $16(94.1 \%)$ & $6(40.0 \%)$ \\
\hline
\end{tabular}

FHPD: family history of psychiatric disorder; ${ }^{*} \mathrm{p}<0.05$.

(53.1\%) in patients with autism. A retrospective chart review shown that $78 \%$ of the autistic patients met DSMIV criteria for $\mathrm{ADHD}^{23}$. Another study found that $55 \%$ of the autistic patients had significant symptoms of ADHD, and 31\% met DSM-IV criteria for ADHD ${ }^{13}$.

The current study shown predominance of hyperactivity-impulsivity symptoms (31.2\%), which is in agreement with the literature ${ }^{17}$. Autistic individuals have less ability to selectively focus on one sound among many in a given environment, being slower and less accurate in detecting the stimulus designated as compared with a control group of individuals without the pathology ${ }^{20}$. Children with comorbid ADHD and autism, however, shows stronger inattention ${ }^{27}$.

The analysis showed no difference in age and frequency of symptoms of ADHD, contrasting to data that found ADHD symptoms common in younger children ${ }^{21}$.

Weather ADHD symptoms in autistic children is a comorbidity or a different phenotype of autistic disorder is still an unsolved problem. It seems that children who meet diagnostic criteria for ADHD an autism have greater impairment in activities than children with only autism, meaning that the presence of both disorders seems to aggravate the functional impairment of the patient. The results of this study indicate that a higher proportion of children with autism and ADHD use psychiatric medications (94.1\%) than children with autism and without symptoms of ADHD (40.0\%) ( $\mathrm{p}<0.032)$. The medications in use belong to four different drug classes: antipsychotics, anticonvulsants, benzodiazepines and antidepressants, reflecting the absence of specific treatment for autistic children with symptoms of ADHD. Despite the use 
of medications, the significant symptoms of ADHD remained in the children. These data reflect need of a more specific and effective pharmacotherapy for these individuals. A large number of studies suggest benefit of psychostimulants in ADHD symptoms of autistic children ${ }^{4,27-32}$. The methylphenidate, however, may be associated with social distance and irritability, as adverse effects, in autistic children ${ }^{14,32}$.

There are some limitations of the current study that should be outlined. First is the small size of the sample, which made it impossible to make a multivariate analysis. Second the intellectual level of patients was not assessed, and mental retard can be a confounder, because can be associated with ADHD symptoms in a autistic child. Third as it is a cross-sectional study, it is important consider that the symptoms of hyperactivity may being generated or exacerbated by medications children are using. Finally this is a sample of children who are in specialized school for autistic spectrum disorder, not reflecting, therefore, data from the general population of autistic patients.

\section{REFERENCES}

1. American Psychiatric Association. Diagnostic and Statistical Manual of Mental Disorders. $4^{\text {th }}$ edition. Washington, DC, 2000.

2. Rapin I. Autistic children: diagnosis and clinical features. Pediatrics 1991;87: 751-760.

3. Rubenstein J, Lotspeich L, Ciaranello R. The neurobiology of developmental disorders. Adv Clin Child Psychol 1999;13:1-52.

4. Holtmann M, Bolte S, Poustka F. Attention deficit hyperactivity disorder symptoms in pervasive developmental disorders: association with autistic behavior domains and coexisting psychopathology. Psychopathology 2007;40:172-177.

5. Bradley EA, Summers JA, Wood HL, Bryson SE. Comparing rates of psychiatric and behavior disorders in adolescents and young adults with severe intellectual disability with and without autism. J Autism Dev Disord 2004;34:151-161.

6. Olley JG, Gutentag SS. Autism: historical overview, definition and characteristics. In: Jager DB (Ed.). Autism: identification, education and treatment. $2^{\text {nd }}$ Ed. New Jersey: Lawrence Erlbaum Associates Publishers, 1999.

7. Wong V. Epilepsy in children with autistic spectrum disorder. J Child Neurol 1983;8:316-322.

8. Bailey $A$, Bolton $P$, Butler $L$, et al. Prevalence of the fragile $X$ anomaly amongst autistic twins and singletons. J Child Psychol Psychiatry 1993;34:673-688.

9. Kent L, Evans J, Paul M, Sharp M. Comorbidity of autistic spectrum disorders in children with Down syndrome. Dev Med Child Neurol 1999;4:153-158.

10. Stahlberg O, Soderstrom H, Rastam M, Gillberg C. Bipolar disorder, schizophrenia and other psychotic disorders in adults with childhood onset AD/HD and/or autism spectrum disorders. J Neural Transmission 2004;111:891-902.

11. Sverd J.Psychiatric disorders in individuals with pervasive developmental disorder. J Psychiatr Practice 2003;9:111-127.

12. Ghaziuddin M, Ghaziuddin N, Greden J. Depression in persons with autism: implications for research and clinical care. J Autism Dev Disord 2002;32:299-306.

13. Leyfer OT, Folstein SE, Bacalman S, et al. Comorbid psychiatric disorders in children with autism: interview development and rates of disorders. J Autism Dev Disord 2006;36:849-861.

14. Reiersen AM, Todd RD. Co-occurrence of ADHD and autism spectrum disorders: phenomenology and treatment. Expert Rev Neurotherapeutics 2008; 8:657-669.

15. Goldstein S, Schwebach AJ. The comorbidity of pervasive developmental disorder and attention deficit hyperactivity disorder: results of a retrospective chart review. J Autism Dev Disord 2004;34:329-339.

16. Hattori J, Ogino T, Abiru K, Nakano K, Oka M, Ohtsuka Y. Are pervasive developmental disorders and attention-deficit/hyperactivity disorder distinct disorders? Brain Dev 2006;6:371-374.

17. Lee DO, Ousley OY. Attention-deficit hyperactivity disorder symptoms in a clinic sample of children and adolescents with pervasive developmental disorders. J Child Adolescent Psychopharmacol 2006;16:737-746.

18. Pliszka SR, Carlson CL, Swanson JM. ADHD with comorbid disorders: clinical assessment and management. New York: The Guilford Press, 1999.

19. Luteijn, EF, Serra M, Jackson S. How unspecified are disorders of children with a pervasive developmental disorder not otherwise specified? A study of social problems in children with PDD-NOS and ADHD. Eur Child Adolescent Psychiatry 2000;9:168-179.

20. Teder-Sälejärvi WA, Pierce KL, Courchesne E, Hillyard SA. Auditory spatial localization and attention deficits in autistic adults. Cogn Brain Res 2005;23:221-234.

21. Yoshida Y, Uchiyama T. The clinical necessity for assessing attention deficit/ hyperactivity disorder (AD/HD) symptoms in children with high-functioning pervasive developmental disorder (PDD). Eur Chil Adolescent Psychiatric 2004;13:307-314

22. Sinzig JK, Lehmkuhl G. Autism and ADHD - are there common traits? Fortsch Neurologie-Psychiatrie 2007;75:267-274.

23. Pondé MP, Freire ACC. Prevalence of attention deficit hyperactivity disorder in schoolchildren in the city of Salvador, Bahia, Brazil. Arq de Neuropsiquiat 2007:65:240-244.

24. Rutter M, Schopler E. Classification of pervasive developmental disorders: some concepts and practical considerations. J Autism Dev Disord 1992;22: 459-482.

25. Novaes CM, Pondé MP, Freire ACC. Control of psychomotor agitation and aggressive behavior in patients with autistic disorder: a retrospective chart review. Arq Neuropsiquiatr 2008;66:646-651.

26. Brasil HH. Desenvolvimento da versão brasileira da K-SADS-PL (Schedule for Affective Disorders and Schizophrenia for School Aged Children Present and Lifetime Version) e estudo de suas propriedades psicométricas Tese. Universidade Federal de São Paulo. Escola Paulista de Medicina. São Paulo, 2003.

27. Santosh PJ, Baird G, Pityaratstian N, Tavare E, Gringras P. Impact of comorbid autism spectrum disorders on stimulant response in children with attention deficit hyperactivity disorder: a retrospective and prospective effectiveness study. Child Care Health Dev 2006;32:575583.

28. Hazell P. Drug therapy for attention-deficit/hyperactivity disorder-like symptoms in autistic disorder. J Pediatrics Child Health 2007;43:19-24.

29. Jahromi LB, Kasari CL, McCracken JT, et al. Positive effects of methylphenidate on social communication and self-regulation in children with pervasive developmental disorders and hyperactivity. J Autism Dev Disord 2001;39:395-404.

30. Parikh MS, Kolevzon A, Hollander E. Psychopharmacology of aggression in children and adolescents with autism: a critical review of efficacy and tolerability. J Child Adolescent Psychopharmacol 2000;18:157-178.

31. Posey DJ, Aman MG, McCracken JT, et al. Positive effects of methylphenidate on inattention and hyperactivity in pervasive developmental disorders: an analysis of secondary measures. J Soc Biol Psychiatry 2005;6:538-544.

32. Research Units on Pediatric Psychopharmacology Autism Network. Randomized, controlled, crossover trial of methylphenidate in pervasive developmental disorders with hyperactivity. Arch Gen Psychiatry 2005;62:1266-1274. 